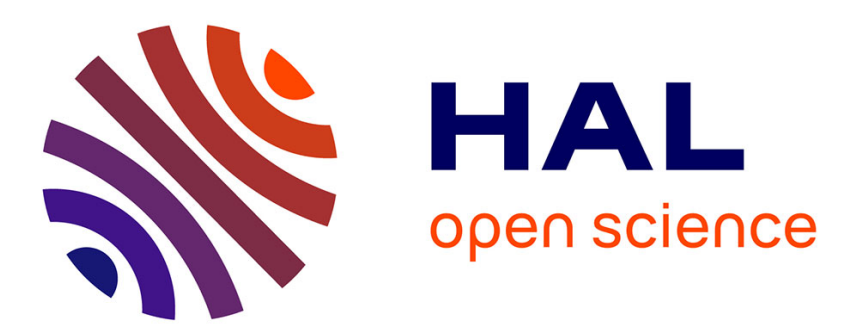

\title{
Residential Electrical and Thermal Storage Optimisation in a Market Environment
}

\author{
Carlos Adrian Correa Florez, Alexis Gerossier, Andrea Michiorri, Robin \\ Girard, Georges Kariniotakis
}

\section{- To cite this version: \\ Carlos Adrian Correa Florez, Alexis Gerossier, Andrea Michiorri, Robin Girard, Georges Kariniotakis. Residential Electrical and Thermal Storage Optimisation in a Market Environment. CIRED 2017 - 24th International Conference on Electricity Distribution, Jun 2017, Glasgow, United Kingdom. pp.1967 - 1970, 10.1049/oap-cired.2017.1086 . hal-01518380}

\section{HAL Id: hal-01518380 \\ https://hal.science/hal-01518380}

Submitted on 4 May 2017

HAL is a multi-disciplinary open access archive for the deposit and dissemination of scientific research documents, whether they are published or not. The documents may come from teaching and research institutions in France or abroad, or from public or private research centers.
L'archive ouverte pluridisciplinaire HAL, est destinée au dépôt et à la diffusion de documents scientifiques de niveau recherche, publiés ou non, émanant des établissements d'enseignement et de recherche français ou étrangers, des laboratoires publics ou privés. 


\section{RESIDENTIAL ELECTRICAL AND THERMAL STORAGE OPTIMISATION IN A MARKET ENVIRONMENT}

\author{
Carlos Adrian CORREA-FLOREZ \\ MINES-ParisTech, PSL - Research \\ University - France \\ carlos-adrian.correa_florez@mines- \\ paristech.fr \\ Robin GIRARD \\ MINES-ParisTech, PSL - Research University - France \\ robin.girard@mines-paristech.fr
}

\author{
Alexis GEROSSIER \\ MINES-ParisTech, PSL - Research \\ University - France \\ alexis.gerossier@mines-paristech.fr
}

\author{
Andrea MICHIORRI \\ MINES-ParisTech, PSL - Research \\ University - France \\ andrea.michiorri@mines-paristech.fr
}

Georges KARINIOTAKIS

MINES-ParisTech, PSL - Research University - France georges.kariniotakis@mines-paristech.fr

\begin{abstract}
This paper presents a method for the energy management of a set of smart homes, in which batteries, thermal storage and demand response are considered as flexibilities in order to achieve minimum operation costs. To cope with the uncertainty of load forecast, a two-stage stochastic optimization process is proposed, in which the first stage decision is the committed energy to be purchased, and the second stage returns the devices' setpoints. This methodology has been developed in the context of the Horizon 2020 project SENSIBLE as part of the tasks related to the use case, Flexibility and Demand Side Management in Market Participation.
\end{abstract}

\section{NOMENCLATURE}

$t, q, h, i$

Indexes for time step, quantile (scenario), household and demand response cut

$T, n_{q}, n_{h}, n_{i}$ Number of time steps, quantiles, households and demand response cuts

$P_{t}^{G} \quad$ Power drawn from the grid at time $t$

$P_{t, q, h, i}^{D R} \quad$ Demand response power at time $t$, scenario $q$, household $h$ and cut $i$

$P_{t, q}^{c h} / P_{t, q}^{d c h} \quad$ Power charge/discharge in the battery for time $t$ and scenario $q$

$X_{t, q} \quad$ State of Charge of battery at time $t$ and scenario $q$

$Y_{t, q, h}$

$H_{t, q, h}$ State of Charge of Electric Water Heaters (EWH) in house $h$, at time $t$ and scenario $q$

time $t$, and scenario $q$

$\pi_{t} \quad$ Spot prime at time $t$

$C_{i}^{D R} \quad$ Price of demand response program for step $i$

$D_{t, q, h} \quad$ Electricity demand at time $t$, scenario $q$ and house $h$

$P_{t}^{p v} \quad$ Power injected by the solar panel at time $t$

$\eta_{c h} / \eta_{d c h} \quad$ Charging/discharging efficiency of battery

$R / C$ Thermal resistance/capacitance of the

EWH

$p_{q}$
Probability of scenario $q$

\section{INTRODUCTION}

One of the main complementary actions when integrating high shares of renewable energy sources into distribution grids is to deploy storage devices, as well as active demand for the provision of flexibility. At "smart home" level, in addition to classic electrochemical storage options, recent years have seen a significant increase in thermal storage (i.e. electric water heaters), PV panels and active demand, which can improve operation efficiency at multiple levels.

Regarding management models for joint thermal and electric storage technologies at the residential level, existing approaches include the one presented in [1], which proposes a residential microgrid, where thermal and electric storage make it possible to shave the demand peak and enhance the system's self-sufficiency. The approach in [2] presents a methodology for intraday management of PV and Electric Water Heaters (EWH) in an LV network, and the EWH acts as a flexible load in order to achieve a minimum operation cost.

Reference [3] presents an optimization problem for the day-ahead market that minimizes retailer costs represented by import/export and gas costs, and also expected balancing costs in real-time operation. The model includes thermal load and electro-thermal storage, which can generate or consume power. A recent paper [4] presents a cooperative scheme in a smart residential building for optimal management of resources, considering batteries, thermal storage and electric vehicles.

This paper presents a method for the energy management of a set of smart homes, in which batteries, thermal storage and demand response are considered as flexibilities in order to achieve minimum operation costs. The proposed Home Energy Management System (HEMS) is evaluated on a case study comprising 40 households, in which a PV plant, a battery, individual demand response and EWHs are considered to minimize the operation costs of the smart home portfolio and determine the devices' appropriate set points. The work presented here was performed within the frame of the EU Horizon 2020 project SENSIBLE (Storage Enabled Sustainable Energy for Buildings and Communities) [5]. The SENSIBLE use case "Flexibility and demand side 
management in market participation" [6], assumes a retailer, or other energy service company, which aggregates a number of customers and participates in a market in order to optimize its electricity costs and add value to the flexibilities that customers can offer.

To reflect a more realistic analysis, we forecast the households' load behaviour using data from the residential energy management equipment in SENSIBLE's Evora real world demonstrator [6,7].

\section{PROPOSED SMART HOME ENERGY MANAGEMENT SYSTEM}

The proposed HEMS aims to manage a physical system composed by a building that integrates several households, equipped with a solar panel and an electrical energy storage device (ESS) (i.e. li-ion battery), and is connected to the main grid. Each household requires the supply of a total electrical base load and a thermal load that has to be met by an EWH, which can also store thermal energy. In addition, demand response (DR) resources need to be managed in each of these households.

In general, EWH input and electrical load during the $24 \mathrm{~h}$ period can be met by the main grid, the solar panel and the injected power from the batteries. The idea is to propose an HEMS that can achieve the minimum operation cost by adjusting the device setting in order to correspond with the DR capabilities and optimally manage resources. The scheme of the proposed HEMS is shown in figure 1 .

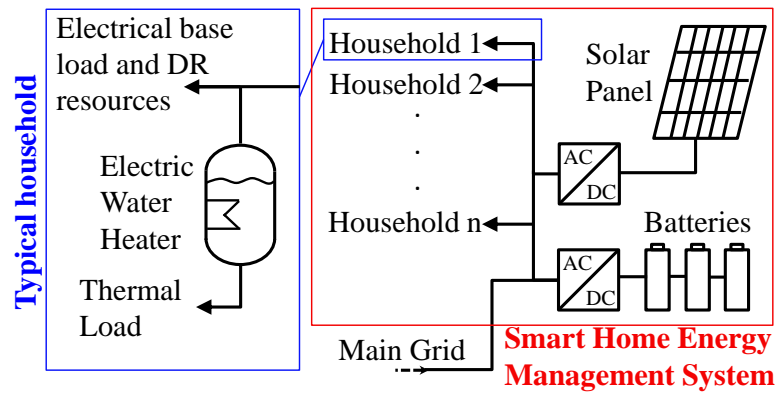

Figure 1. Schematic diagram of the proposed HEMS

As shown, the battery and the PV serve all households in the system, whereas the thermal storage and the DR resources are independently associated with individual households.

One feature of the proposed HEMS is the possibility to independently control the ESS and EWH. This means that the secondary grid does not directly feed the thermostatic load. In other words, this load is fed by the available stored energy in the TES, and the input for the EWH is seen as a load from the secondary network.
In addition, the proposed HEMS considers the possibility of load managing through a DR program, where customers are paid an incentive corresponding to the load cut [8]. It is supposed that the portfolio manager (HEMS operator) is able to reduce or cut load to specific clients (households) by means of flexible contracts, in order to obtain the minimum operational cost while taking advantage of the system's integrated resources. A predefined number of consecutive steps to disconnect load is considered and a cost is associated with each step.

The SENSIBLE project explores integrating available technologies into the local power grid through 3 European demonstrators. The Evora demonstrator develops energy management applications and has therefore deployed smart meters in a localized neighbourhood of the city of Evora, Portugal. This smart meter roll-out features forecasting models developed to predict the electrical load demand of individual households.

\section{Electrical load forecasting}

To predict the electrical demand of one household for the next day, the model uses the demand during the previous week and the outside temperature predicted for the next day. By means of quantile smoothing spline fitting, it is possible to predict day-ahead demand $\hat{d}_{t}$ at instant $t$, as the sum of three functions:

$$
\hat{d}_{t}=f_{1}\left(d_{t-24}\right)+f_{2}\left(\overline{d_{t}}\right)+f_{3}\left(\widehat{T}_{t}\right)
$$

where $d_{t-24}$ is the demand 24 hours before the instant to be predicted, $\bar{d}_{t}$ the median demand of the previous week and $\widehat{T}_{t}$ the predicted temperature given by a weather forecast model.

After quantile regression, a set of forecast quantiles is obtained. Instead of a single-point value, $10 \%, 20 \%, \ldots$, $90 \%$ values are obtained and respectively associated with a $10 \%, 20 \%, \ldots, 90 \%$ chance of measuring a lower actual demand at the instant predicted. This probabilistic forecasting of electrical demand is of raising interest in the literature (see review [9]). In the present work, each scenario is associated with a quantile $q$.

\section{MATHEMATICAL MODEL}

The model presented minimizes HEMS operational costs by scheduling battery power charge and discharge, the power injected into the EWHs, the DR resources and the power exchanged with the main grid. The proposed optimization model is shown and described in equations (2)-(16) and aims to minimize the expected day-ahead operation cost for the smart home portfolio manager, in the presence of different load patterns. The objective function considers the import energy cost and the cost of the DR program due to load reduction on successive steps or cuts. The optimization is performed in two stages: the 
first stage fixes the power drawn from the grid for the day-ahead market, and the recourse decision of the second stage is related to the set points of the battery, EWHs, and the DR program.

Equation (3) expresses the power balance with mixed first and second stage variables, where electrical base load and thermal load have to be supplied by the available resources, the purchased power in the wholesale market and adjusted by the power cuts due to the DR program. It is important to note that load balance includes demand shifted $\left(P_{t, q, h}^{s h}\right)$, to offset power cuts in other periods. Constraint (8) shows that all power cuts by the DR are shifted to other times of day, which leads to the same energy consumption despite the presence of a DR program.

$$
\min \sum_{t=1}^{T}\left(\pi_{t} P_{t}^{G}+p_{q} \sum_{q=1}^{n_{q}} \sum_{h=1}^{n_{h}} \sum_{i}^{n_{i}} C_{i}^{D R} P_{t, q, h, i}^{D R}\right)
$$

s.t.

$$
\begin{aligned}
& \sum_{h=1}^{n_{h}}\left(D_{t, q, h}+H_{t, q, h}+P_{t, q, h}^{s h}-\sum_{i}^{n_{i}} C_{i}^{D R} P_{t, q, h, i}^{D R}\right) \\
& -P_{t}^{G}+P_{t, q}^{c h}-P_{t, q}^{d c h}-P_{t}^{p v}=0 \\
& X_{t, q}=X_{t-1, q}+\eta_{c h} P_{t-1, q}^{c h}-P_{t-1, q}^{d c h} / \eta_{d c h} \\
& X_{1, q}=X_{T, q} \\
& Y_{t, q, h}=Y_{t-1, q, h}+H_{t, q, h}-\frac{Y_{t-1, q, h}}{R C}-D_{t, q, h}^{t h} \\
& Y_{1, q}=Y_{T, q} \\
& \sum_{t=1}^{T} \sum_{i}^{n_{i}} P_{t, q, h, i}^{D R}=\sum_{t=1}^{T} P_{t, q, h}^{S h} \\
& 0 \leq P_{t}^{G} \leq \frac{t=1}{P_{t}^{G}} \\
& 0 \leq P_{t, q, h, i}^{D R} \leq \overline{P_{t, q, h, l}^{D R}} \\
& 0 \leq P_{t, q}^{c h} \leq \overline{P_{t, q}^{c h}} \\
& 0 \leq P_{t, q}^{d c h} \leq \overline{P_{t, q}^{d c h}} \\
& X_{t, q} \leq X_{t, q} \leq \overline{X_{t, q}} \\
& 0 \leq H_{t, q, h} \leq \overline{H_{t, q, h}} \\
& 0 \leq Y_{t, q, h} \leq \overline{Y_{t, q, h}} \\
& t:\{1, \ldots, T\} ; q:\left\{1, \ldots, n_{q}\right\} ; h:\left\{1, \ldots, n_{h}\right\} ; \\
& i:\left\{1, \ldots, n_{i}\right\}
\end{aligned}
$$

In this way, the portfolio manager can handle available demand to be included in the DR program so that customers can shift some of their loads to achieve the minimum operational cost of the entire system [9]. Equations (4) and (6) describe the energy state of the battery and the EWH, respectively. In these constraints, the energy stored in time period $t+l$ is determined by the previous state of charge and the charge/discharge of the device in time period $t$ with the corresponding efficiency. It is important to mention that the term including $R$ and $C$ in equation (6) represents the energy dissipation in the EWH as a measure of energy loss, as proposed in [3]. All variable limits are shown in constraints (9)-(16).

\section{RESULTS}

The proposed model is coded in Python using a DELL desktop computer with an Inter (R) Xeon (R) CPU E31245 @3.5GHz. The considered case study includes 40 households at the Evora demonstration site in Portugal. The forecasts of the electric base load of each household are generated using the method described above and based on data collected from smart meters and Numerical Weather Predictions from ECMWF (European Centre for Medium-Range Weather Forecasts) on a typical day in November 2015. The thermal load is separated from the electrical base load and follows the pattern from [4], and its maximum level is adjusted to $25 \%$ of that of the electrical load, in order to reflect more realistic behaviour. Electricity prices are those of a typical day in November 2015 taken from the EPEX-European Power Exchange database.

The maximum and minimum battery energy capacities are $80 \%$ and $20 \%$, respectively, based on reference [11]. Charging and discharging efficiency are assumed to be $95 \%$, and nominal power and capacity are $50 \mathrm{~kW}$ and 100 $\mathrm{kWh}$, respectively; the size of the PV is $15 \mathrm{kWp}$ and its power injection is assumed to be known.

Rated power/energy for the EWH, according to commercially available devices, is $3 \mathrm{~kW} / 7.1 \mathrm{kWh}$ respectively [12], and thermal resistance/capacitance are $568\left({ }^{\circ} \mathrm{C} / \mathrm{kW}\right) / 0.3483\left(\mathrm{kWh} /{ }^{\circ} \mathrm{C}\right)$ according to [3].

The DR program is included by considering 3 consecutive steps in load reduction. Each step is assigned maximum values of $10 \%, 15 \%$ and $20 \%$ of each household load for the specific time period. The associated cost for each power cut is $15 \%, 22 \%$ and $45 \%$ of the maximum sport price. The bidding curve for load is based on a load reduction of $10 \%, 15 \%$ and $20 \%$ of aggregated demand. Similar percentages have been achieved for DR programs in other electricity markets. For further details and references see also [13].

A first test is carried out to determine the impacts of having only the flexibility given by the battery (uncoordinated scheme), versus the possibility of coordinated control for both battery and thermal storage.

As an example, the analyzed load pattern is related to the quantile $50 \%$ under a deterministic approach, i.e. a unique scenario. The average daily cost for covering electricity consumption cost per home assuming that no other options are available (generation or storage) is 
$€ 18.16$. Considering only PV injection (assumed to be known from forecasts), the cost is $€ 13.00$ (base case). Different scenarios are tested to assess the contribution of each technology in reducing costs as shown in the table below.

\begin{tabular}{|c|c|c|c|c|c|}
\hline \multirow{2}{*}{$\begin{array}{c}\text { Case } \\
\#\end{array}$} & \multicolumn{3}{|c|}{ Used flexibility } & & Improvement \\
\cline { 2 - 5 } & $\begin{array}{c}\text { Electr. } \\
\text { storage }\end{array}$ & $\begin{array}{c}\text { Thermal } \\
\text { storage }\end{array}$ & $\begin{array}{c}\text { Active } \\
\text { demand }\end{array}$ & $\begin{array}{c}\text { Cost } \\
(€)\end{array}$ & $\begin{array}{c}\text { w.r.t. base } \\
\text { case }\end{array}$ \\
\hline $1^{*}$ & Yes & No & No & 10.2 & $21.4 \%$ \\
\hline 2 & Yes & No & Yes & 8.8 & $32.3 \%$ \\
\hline 3 & Yes & Yes & Yes & 7.7 & $40.7 \%$ \\
\hline
\end{tabular}

Table 1. Cost comparison. The first case indicates demand results from aggregating thermal and electrical load

When independent control of the thermal storage is not allowed (case 1), a $21.4 \%$ cost reduction is achieved by using only the battery to minimize the cost. When thermal and power storage are permitted to be controlled independently (but coordinated), a greater cost reduction is obtained, showing that including thermal storage as another flexibility leads to a decrease in the cost. In addition, including active demand makes it possible to reduce the operation costs.

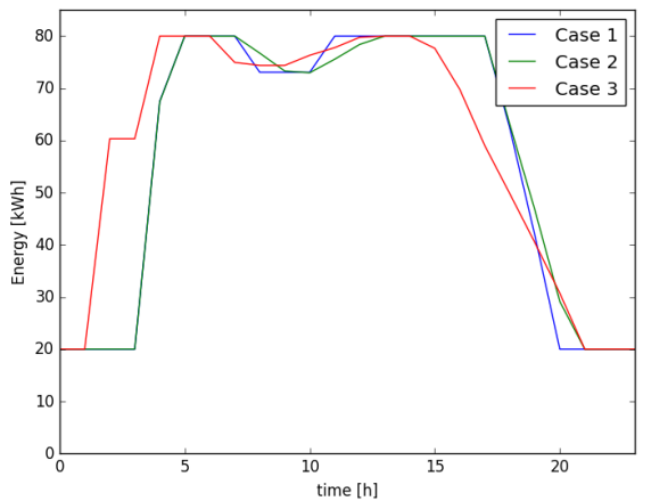

Figure 2. State of charge of battery for the three cases.

Figure 1 shows the state of charge of the battery for each of the three analyzed cases. As shown, active demand and coordinated thermal storage change the pattern of the stored energy.

Figure 2 shows how active demand responds to help minimize overall cost, by shifting demand to the early hours when electricity prices are lower. Of course, further developments and more detailed models could lead to better fitting of the shifting capabilities, in line with customers' contracts and the real-life limitations.

It is worth mentioning that in the case of the EWHs (figure 3), which can only absorb power $(H)$, charging occurs in all cases when $\mathrm{t}=4$. With this input, the stored energy is sufficient to satisfy the thermal load for the remaining time periods, even including the energy loss.
If the set points of the devices for the previous simulation are applied for a different load quantile, extra costs have to be added in order to face imbalances in intraday operation. As an example, if the load uncertainty realized corresponds to quantile 8, the operation increases by $€ 4.1$ (assuming a conservative scenario where the balancing price and spot price are equal). To reduce risks when determining the set points for the day-ahead operation of the HEMS, and to avoid the costs of over/under contracting (and consequently selling/buying) and the corresponding financial losses, the two-stage model in (2)-(16) is used.

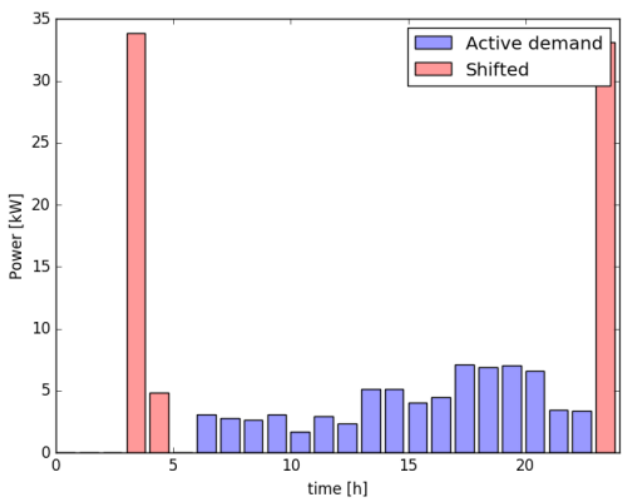

Figure 3. Demand response behaviour

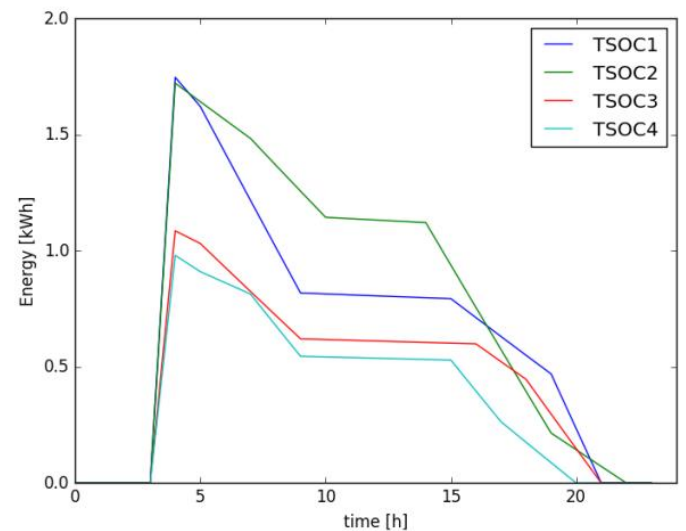

Figure 4. State of charge of EWHs.

The expected cost given by (Eq 2) is $€ 12.2$. This operation scheme has the characteristic of withstanding any load pattern given by quantiles 1 to 9, without any extra cost due to imbalance. The first stage variable, which is the power drawn from the grid, can be seen in figure 4. From this behaviour it can be concluded that the proposed scheme reduces the dependency on the main grid, decreasing the power exchange for several time periods. Hence, demand is met thanks to adequate management of the storage devices and the active demand.

Figure 5 shows the battery state of charge for each of the 9 scenarios. The selection of one of the settings is related 
to an optimal management plan for the day-ahead operation, which explains the different paths for the SOC. The available energy in the battery allows power exchanges between loads and EWH.

This figure also shows (blue dotted curve) the SOC for the scenario related to quantile 5 , when embedded in the two-stage optimization process. If compared to the SOC (red plot) in figure 1, it can be noted that the stored energy actually changes, even though it is related to the same quantile, given that the deterministic approach focuses on optimizing under a single scenario losing robustness to withstand other load patterns.

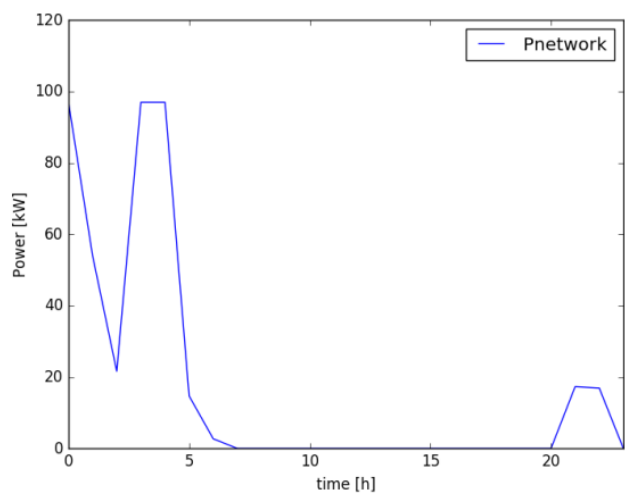

Figure 5. Power drawn from the distribution grid.

\section{CONCLUSION}

In this paper, we proposed a two-stage optimization model for home energy management. This approach makes it possible to fix the value of committed energy to be purchased, even when the realization of the load uncertainty is unknown. The purchase decision is carried out in the first stage and then the recourse decision is related to the devices' set points, which is done in the second stage.

We also showed that the coordination of thermal and electrochemical storage leads to cost minimization in a context of smart energy management, and that results can be extended to real-life testbeds, such as the Evora demonstrator in Portugal.

\section{ACKNOWLEDGEMENT}

This work was carried out as part of the research and innovation project SENSIBLE (Storage ENabled SustaInable energy for BuiLdings and communitiEs www.h2020-projectsensible.eu), which has received funding from the European Union under the Horizon 2020 Framework Programme grant agreement No 645963.

\section{REFERENCES}

[1] G. Comodi, et al, "Multi-apartment residential microgrid with electrical and thermal storage devices: Experimental analysis and simulation of energy management strategies",

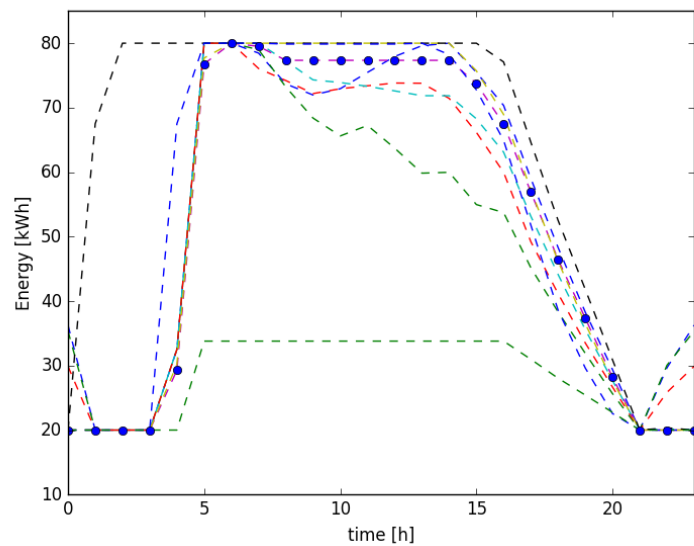

Figure 6. Energy stored in battery for all scenarios.

Applied Energy, vol. 137, pp. 854-866, 2015

[2] $\mathrm{Li}, \mathrm{T}$. Borsche, and G. Andersson, "PV integration in Low-Voltage feeders with Demand Response, "2015 IEEE Eindhoven PowerTech, PowerTech 2015, 2015.

[3] N. Good, E. Karangelos, A. Navarro-Espinosa, and P. Mancarella, "Optimization under Uncertainty of Thermal Storage-Based Flexible Demand Response with Quantification of Residential Users' Discomfort", IEEE Transactions on Smart Grid, vol. 6, no. 5, pp. 2333-2342, 2015.

[4] A. Ouammi, "Optimal Power Scheduling for a Cooperative Network of Smart Residential Buildings," vol. 7, no. 3, pp. 1317-1326, 2016.

[5] Project SENSIBLE. [Online]. www.h2020-projectsensible.eu

[6] R. Andre et al. "Energy services bridging the gap between residential flexibility and energy markets", CIRED 2017, in revision.

[7] R. Mendes André et al, "Customers' flexibility valued in market and regulated environment", In proceedings of CIRED 2016 Workshop, Paper 0395, Helsinki, Finland, 14-15 June.

[8] P. Faria, et al, "Particle swarm optimization applied to integrated demand response resources scheduling," in Computational Intelligence Applications In Smart Grid (CIASG), 2011 IEEE Symposium, April 2011, pp. 1-8.

[9] Hong and S. Fan, "Probabilistic electric load forecasting: A tutorial review" International Journal of Forecasting, vol. 32, no. 3, pp. 914-938, 2016.

[10] W. Hu, et al, "Fuzzy adaptive particle swarm optimisation for power loss minimisation in distribution systems using optimal load response," Generation, Transmission Distribution, IET, vol. 8, no. 1, pp. 1-10, Jan 2014

[11] D. Xu, P. Li, and B. Zhao, "Optimal scheduling of microgrid with consideration of demand response in smart grid" in Networking, Sensingand Control (ICNSC), IEEE 12th International Conference on, April 2015, pp. 426-431.

[12] Electric space and water heating management system, technical specifications, DIMPLEX Unvented Hot Water Cylinders.

[13] C. A. Correa, G. Marulanda and A. Garces, "Optimal microgrid management in the Colombian energy market with demand response and energy storage," 2016 IEEE Power and Energy Society General Meeting, Boston, MA, 2016, pp. 1-5. 